\title{
PACKING HOUSE E MERCADO PARA ABACAXI
}

LAURA A. SAVITCI *

JOSÉ GASPARINO FILHO *

ROSÂNGELA S.S.FERNANDES LEITE *

FLÁVIA M.M.BLISKA *

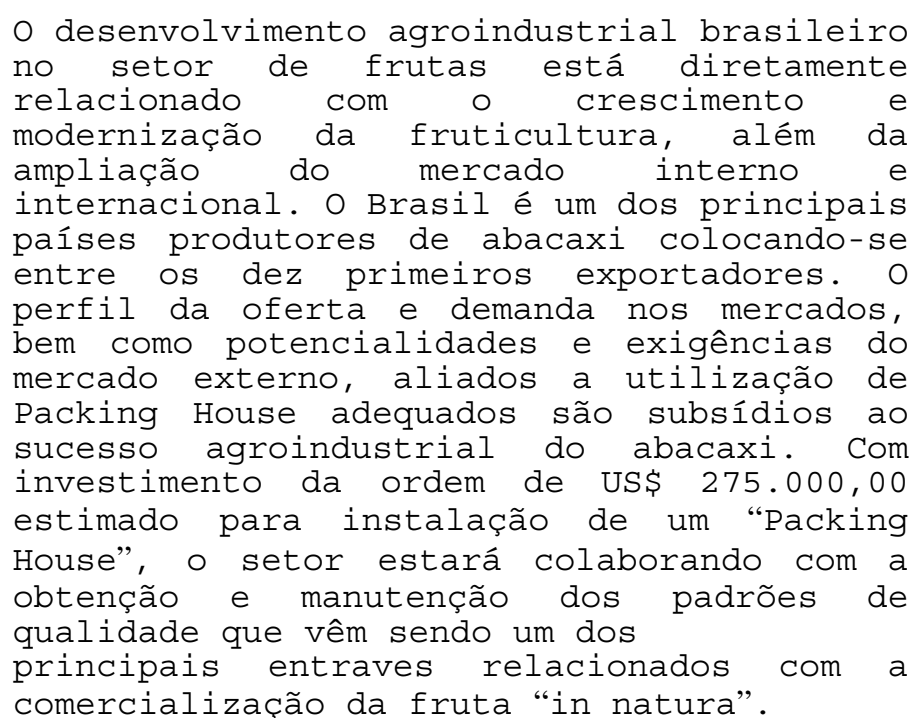

\section{INTRODUÇÃO}

O desenvolvimento agroindustrial no setor de frutas do País está diretamente relacionado com o crescimento e modernização da fruticultura, aliado a ampliação do mercado interno e internacional.

A fruticultura tropical necessita de volume e qualidade para competir no mercado internacional. O mercado interno ainda prioriza preços e qualidade razoável.

* Pesquisadores do Instituto de Tecnologia de Alimentos (ITAL), Campinas, SP.

B.CEPPA, Curitiba, v. 14, n. 2, p. 181-202, jul./dez.1996 
O Brasil, o principal produtor mundial de frutas, ocupa a terceira posição no ranking entre os países produtores e os dez primeiros exportadores de abacaxi (5).

Existem centenas de variedades de abacaxi, no entanto, são considerados como mais importantes no Brasil as cultivares Pérola e Smooth Cayenne. A melhor colocação no mercado interno como fruta fresca é do Pérola, graças as suas características de polpa suculenta e adocicada que atendem às preferências do brasileiro. O mercado argentino também aprecia este tipo de fruta. No caso de industrialização e/ou exportação (exceto para a América do Sul) deve-se priorizar o plantio do Smooth-Cayenne. Esse cultivar atende bem às necessidades da indústria: consistência firme, coloração amarela, acidez, formato cilíndrico (facilita enlatamento); além de enquadrar-se no padrão e gosto do europeu (coloração intensa e sabor mais ácido).

As frutas com o peso entre 0,9 e $1,5 \mathrm{~kg}$ são preferidas pelo consumidor europeu. Existe também um mercado de luxo (principalmente no Reino Unido) para frutas com peso de 2,0 a $2,5 \mathrm{~kg}$. As exigências de frutas com coroas de 5 a $13 \mathrm{~cm}$ são destinados ao mercado europeu (12).

A interação dos conhecimentos técnicos propicia infraestrutura adequada à projetos agroindustriais, ou seja, o conhecimento do perfil dos mercados, determinando a produção e qualidade a ser obtida e mantida em todas as fases de comercialização. A instalação de "packing house", dentro desse contexto, promoverá o manuseio correto e a obtenção da qualidade adequada.

\section{OBJETIVOS}

No sentido de fornecer subsídios ao desenvolvimento agroindustrial e de exportação para o abacaxi pretende-se levantar a oferta e a demanda no mercado interno e externo, bem como estabelecer o perfil industrial para instalação de "Packing Houses" adequadas para a seleção e valorização da fruta.

\section{MATERIAL E MÉTODOS}

O trabalho foi desenvolvido com base em dados secundários publicados por órgãos oficiais do País e exterior, e levantamento de dados primários junto à entidades e/ou técnicos relacionados com a área no Brasil.

Foi caracterizado um "Packing House" com capacidade de produção, manuseio e equipamentos adequados, bem como 
investimentos necessários através da experiência da seção de Engenharia do ITAL e empresas do ramo.

\section{RESULTADOS E DISCUSSÃO}

\subsection{ASPECTOS DE MERCADO}

4.1.1 Oferta e demanda no mercado interno

A oferta de abacaxi no mercado interno basicamente é determinada pela produção brasileira, uma vez que oficialmente inexistem importações.

A produção brasileira de abacaxi voltou a crescer a partir de 1991 e está concentrada em dois principais Estados, ou seja, Paraíba e Minas Gerais. No ano de 1994, a Paraíba com 24\% da produção brasileira e tradicional principal produtor, foi superado pelo Estado de Minas Gerais que atingiu 36\% do total produzido pelo país naquele ano.

- Tabela 1 apresenta a produção brasileira por estados no período de 1988-1994 e a Figura 1 representa a participação dos principais estados brasileiros na produção de abacaxi.

A variação da área colhida nos principais estados produtores de abacaxi no período de 1988 a 1994, é apresentada no Tabela 2. Maiores incrementos foram observados nos Estados do Pará $(+280 \%)$, Espírito Santo (+129\%), Minas Gerais (+19\%) e Bahia (18\%); as principais reduções ocorreram nos estados da Paraíba (-48\%) e Rio Grande do Norte (-42\%).

O comportamento da produtividade brasileira e dos principais estados produtores de abacaxi, no período de 1991/94, é apresentado no Tabela 3 .

O rendimento médio brasileiro tem estado ao redor dos $22 \mathrm{mil}$ frutos/ha ou seja 38 t/ha, muito inferior às 60 t/ha obtidas nas Filipinas e Tailândia. Os melhores rendimentos têm sido dos Estados da Paraíba e São Paulo com respectivamente, 28.562 e $27.032 \mathrm{mil}$ frutos/ha (Tabela 3).

O desestímulo atual pela cultura do abacaxi poderá estar aliado à necessidade de adequada orientação tecnológica desde a indicação edafloclimática, plantio, colheita, manuseio, comercialização, até a industrialização e potencialidade de mercado externo. 
FIGURA 1 - PARTICIPAÇÃO DOS ESTADOS BRASILEIROS NA PRODUÇÃO DE ABACAXI EM \% EM 1994

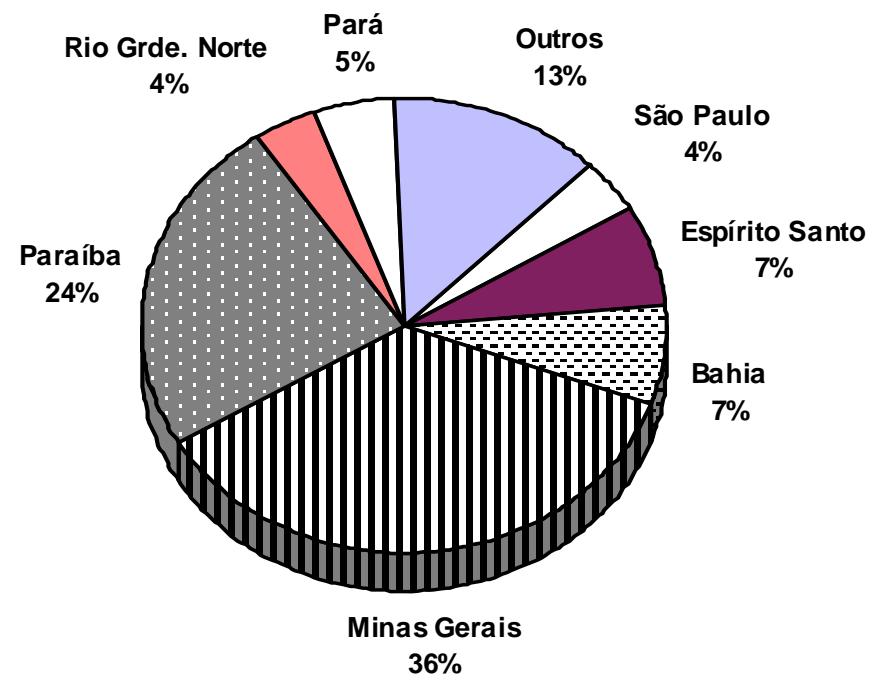

TABELA 2 - VARIAÇÃO PERCENTUAL DA ÁREA COLHIDA DE ABACAXI, NOS PRINCIPAIS ESTADOS PRODUTORES, NO PERÍODO DE 1988-94

\begin{tabular}{lcccc}
\hline UNIDADE DA FEDERAÇÃO & $\begin{array}{c}1988 \\
\text { (ha) }\end{array}$ & $\begin{array}{c}1994 \\
\text { (ha) }\end{array}$ & $\begin{array}{c}\text { Variação no período } \\
\text { (\%) }\end{array}$ \\
\hline São Paulo & 1.587 & 1.560 & -2 \\
Pará & 660 & 2.510 & +280 \\
Paraíba & 16.038 & 8.355 & -48 \\
Rio Grande do Norte & 3.007 & 1.745 & -42 \\
Minas Gerais & 13.765 & 16.348 & +19 \\
Espírito Santo & 1.425 & 3.258 & +129 \\
Bahia & 2.800 & 3.293 & +18 \\
Brasil & 46.079 & 43.617 & -5 \\
\hline
\end{tabular}

Fonte: IBGE, Anuário Estatístico do Brasil Produção Agrícola Municipal. 
TABELA 3 - PRODUTIVIDADE OBTIDA PELOS PRINCIPAIS ESTADOS PRODUTORES DE ABACAXI NO PERÍODO 1991/94

\begin{tabular}{lcccc}
\hline \multirow{2}{*}{ ESTADOS } & \multicolumn{4}{c}{ PRODUTIVIDADE (frutos/ha) } \\
\cline { 2 - 5 } & 1991 & 1992 & 1993 & 1994 \\
\hline Pará & 19.310 & 19.473 & 18.895 & 21.349 \\
Rio Grande do Norte & 22.116 & 20.689 & 20.369 & 22.358 \\
Paraíba & 28.767 & 28.897 & 25.129 & 28.562 \\
Minas Gerais & 19.756 & 20.881 & 21.033 & 20.859 \\
Bahia & 19.691 & 23.297 & 20.182 & 21.711 \\
Espírito Santo & 22.644 & 20.619 & 20.271 & 20.204 \\
São Paulo & 25.133 & 26.889 & 28.101 & 27.032 \\
Brasil & 22.102 & 22.084 & 21.012 & 22.344 \\
\hline
\end{tabular}

Fonte: IBGE

\subsubsection{Custo de produção}

A importância do custo de produção está ligada à formação de preço em nível de produtor, margem de comercialização e a apresentação de preço competitivo ao consumidor final.

A partir de dados fornecidos pela Cooperativa Agrícola de Cotia (CAC) (3) no Estado de São Paulo, estima-se que o custo de produção em 1 hectare esteja em torno de US\$ 3.900,00 para o primeiro ano e US\$ $2.700,00$ para o segundo. O custo da mãode-obra (tratos culturais e colheita) é o mais significativo, sendo responsável por aproximadamente 35\% do total, enquanto fertilizantes e corretivos respondem por $25 \%$, mudas por $16 \%$ e defensivos por $8 \%$ do custo total. A discriminação destes custos está reproduzida no Tabela 4.

o nível de produtividade aproximada estabelecido para o Estado de São Paulo de 27.000 frutos/ha, permite estimar um custo de produção no $2^{\circ}$ ano de US\$ $0,10 /$ fruto de 1,7 kg cada ou US\$ $59,00 / t$.

\subsubsection{Comercialização}

São Paulo e Belo Horizonte são os principais mercados para o abacaxi “in natura” através do CEASA. O abacaxi da Paraíba é preferido pois é mais doce e maior; geralmente os frutos são classificados como grande, médio e pequeno. A variedade preferida é a pérola por ser mais resistente. 
TABELA 4 - CUSTO DE PRODUÇÃO MÉDIO EM 1 ha PARA ABACAXI NO ESTADO DE SÃO PAULO EM 1992

\begin{tabular}{|c|c|c|c|c|c|c|}
\hline DISCRIMINAÇÃO & \begin{tabular}{|l|} 
UNI- \\
DA- \\
DE \\
\end{tabular} & $\begin{array}{c}\text { CUSTO } \\
\text { UNITÁRIO } \\
\text { (US\$) }\end{array}$ & $\begin{array}{c}1^{\circ} \text { ANO } \\
\text { QTD }\end{array}$ & $\begin{array}{c}\text { CUSTO } \\
\text { TOTAL (US\$) }\end{array}$ & $\begin{array}{l}2^{\circ} \text { ANO } \\
\text { QTD }\end{array}$ & $\begin{array}{c}\text { CUSTO } \\
\text { TOTAL } \\
\text { (US\$) } \\
\end{array}$ \\
\hline Aração 2 x MF-265 c/3 discos & hd & 9,05 & 5 & 45,23 & 0 & 0,00 \\
\hline Gradeação 2 x MF-265 c/20 discos & hd & 8,82 & 3 & 26,45 & 0 & 0,00 \\
\hline Calagem MF-265 esparramador & hd & 10,50 & 1 & 10,50 & 0 & 0,00 \\
\hline Total de Preparo do Solo & ha & & & 82,18 & & 0,00 \\
\hline Plantio & hd & 4,96 & 20 & 99,20 & 0 & 0,00 \\
\hline Total de Plantio & & & & 99,20 & & 0,00 \\
\hline Adubação Básica & hd & 4,96 & 10 & 49,60 & 6 & 29,76 \\
\hline Adubação Cobertura & hd & 4,96 & 10 & 49,60 & 10 & 49,60 \\
\hline Aplicação de Herbicida & hd & 4,96 & 6 & 29,76 & 4 & 18,84 \\
\hline Capina Manual & hd & 4,96 & 10 & 49,60 & 15 & 74,40 \\
\hline Proteção de Frutos & hd & 4,96 & 15 & 74,40 & 10 & 49,60 \\
\hline Tratamento de Mudas & hd & 4,96 & 10 & 49,60 & 0 & 0,00 \\
\hline $\begin{array}{l}\text { Pulverização } \\
\text { Jacto Coral B-12/75 }\end{array}$ & hd & 10,62 & 30 & 318,56 & 30 & 318,56 \\
\hline Sulcamento MF-265 & hd & 8,26 & 4 & 33,04 & 0 & 0,00 \\
\hline Total de Tratos Culturais & & & & 654,16 & & 514,76 \\
\hline Calcário Dolomítico & tn & 30,60 & 2.00 & 61,19 & 0.00 & $0 ., 00$ \\
\hline Sulfato de Amônio & tn & 265,56 & 1.80 & 478,01 & 1.80 & 478,01 \\
\hline Cloreto de Potássio & tn & 429,67 & 1.00 & 429,67 & 1.00 & 429,67 \\
\hline Superfosfato Simples & tn & 164,66 & 0.30 & 49,40 & 0.30 & 49,40 \\
\hline Termofosfato Magnesiano BZ & tn & 217,08 & 0.20 & 43,42 & 0.00 & 0,00 \\
\hline Total de Mat. Corrt/Orgânica/Fert & & & & $1.061,69$ & & 957,08 \\
\hline Mudas de Abacaxi & un & 0,03 & 20.000 & 611,49 & 0 & 0,00 \\
\hline Total de Mudas & & & & 611,49 & & 0,00 \\
\hline Contion 800 & $\mathrm{~kg}$ & 14,85 & 8.00 & 118,80 & 8.00 & 118,80 \\
\hline Benlate 500 & $\mathrm{~kg}$ & 27,95 & 6.00 & 167,72 & 6.00 & 167,72 \\
\hline Servim 850 Pn & $\mathrm{kg}$ & 13,98 & 15.00 & 209,65 & 20.00 & 279,54 \\
\hline Total de Defensivos & & & & 496,18 & & 566,06 \\
\hline Transporte Interno & $\mathrm{hm}$ & 8,80 & 20 & 176,03 & 20 & 176,03 \\
\hline Sub-Total S/Colheita & & & & $3.180,92$ & & $2.240,93$ \\
\hline Colheita de Abacaxi & $\mathrm{cX}$ & 0,45 & 1.600 & 720,00 & 1.000 & 450,00 \\
\hline Jornal & $\mathrm{kg}$ & 0,10 & 250 & 25,00 & 250 & 25,00 \\
\hline Total de Colheita & & & & 745,00 & & 475,00 \\
\hline TOTAL GERAL & & & & $3.925,92$ & & $2.715,93$ \\
\hline
\end{tabular}

Fonte: CAC - CC (Cooperativa Agrícola de Cotia - Cooperativa Central).

hd - homem dia.

hm - hora máquina.

cx - caixa.

tn - tonelada. 
No mercado interno de São Paulo, o período de setembro a janeiro concentra os meses de maior oferta do abacaxi, tornando os preços menos atrativos (13).

Quanto a variação de preços o período de março à junho apresenta preços mais elevados sendo os meses de março/abril os de maiores picos. Isso se deve à coincidência com a época da entresafra do abacaxi, conforme Quadro 1.

\section{QUADRO 1 - SAFRA DO ABACAXI VARIEDADE SMOOTH CAYENNE}

\begin{tabular}{|c|c|c|c|c|c|c|c|c|c|c|c|c|c|}
\hline \multirow[t]{2}{*}{ Fruta } & \multirow[t]{2}{*}{ Variedade } & \multicolumn{12}{|c|}{ Meses } \\
\hline & & $\mathrm{J}$ & $\bar{F}$ & $\mathrm{M}$ & $A$ & $\mathrm{M}$ & $\mathrm{J}$ & $\mathrm{J}$ & $A$ & $\mathrm{~S}$ & $\mathrm{O}$ & $\mathrm{N}$ & $\mathrm{D}$ \\
\hline Abacaxi & Smooth Cayenne & 2 & $\geqslant$ & $V$ & & & & & & & & & \\
\hline
\end{tabular}

Fonte: ITAL.

Período de Safra.

A grande maioria do abacaxi é consumido no mercado interno na forma “in natura”. O consumo per capita está diretamente relacionado com o preço do produto e vem crescendo 13,34\% ao ano. Uma das frutas mais apreciadas em todas as regiões metropolitanas tem seu maior consumo em Recife onde chega a $7,69 \mathrm{~kg} / \mathrm{hab} / \mathrm{ano}$, seguido por Goiânia $(3,89 \mathrm{~kg} / \mathrm{hab} / \mathrm{ano})$ e Belo Horizonte $(3,15 \mathrm{~kg} / \mathrm{ha} / \mathrm{ano})$. O consumo em outras grandes capitais como São Paulo, Rio de Janeiro, Porto Alegre, Brasilia, Salvador, Vitória e Curitiba está na faixa de 2,0 $\mathrm{kg} / \mathrm{hab} / \mathrm{ano}(13)$.

O preço pago no atacado no período de 1991/94 nos principais estados produtores é apresentado no Quadro 2 .

\section{QUADRO 2 - PREÇO MÉDIO PAGO NO ATACADO DAS CEASAS}

\begin{tabular}{|c|c|c|c|c|c|c|}
\hline Estado & $\begin{array}{c}1991 \\
\mathrm{US} \$ \mathbf{K g}\end{array}$ & $\begin{array}{c}1992 \\
\mathrm{US} \$ / \mathrm{Kg}\end{array}$ & $\begin{array}{c}1993 \\
\mathrm{US} \$ / \mathrm{Kg}\end{array}$ & & $\begin{array}{c}1994 \\
\mathrm{US} \$ / \mathrm{Kg}\end{array}$ & \\
\hline & & & & março & abril & maio \\
\hline Bahia* & 0,18 & 0,15 & 0,18 & 0,23 & & \\
\hline Paraíba* & & & & 0,15 & 0,10 & 0,10 \\
\hline
\end{tabular}

* Peso médio por abacaxi $=1,7 \mathrm{Kg}$

$\mathrm{R} \$ 1,0 \odot=$ US\$ $\odot, 95$

Fonte: CEASA 


\subsubsection{Oferta e demanda no mercado externo}

\subsubsection{Produção}

As principais zonas produtoras de abacaxi no mundo situam-se entre os trópicos de Câncer e Capricórnio, normalmente em regiões litorâneas. Apenas uma dezena de países produtores exportam o produto. Em 1990, foram comercializadas cerca de 592 mil toneladas de abacaxi fresco e $472 \mathrm{mil}$ toneladas em conserva.

Segundo dados estatísticos da FAO, a produção mundial de abacaxi em 1993 beirou 11,7 milhões de toneladas. Isto correspondeu a aumento de $15 \%$ em relação aos 10 milhões de toneladas registradas em 1989.

o aumento de produção nos últimos anos ocorreu principalmente na Ásia, particularmente na Tailândia e Filipinas, devido a crescimento da área plantada e à adoção de técnicas culturais mais aprimoradas. É importante notar que este crescimento está intimamente associado ao movimento de descentralização da produção de grandes companhias americanas, que optaram por grandes investimentos nestes países. As duas principais companhias são a Castle \& Cooke Inc (marca "Dole") e a Del Monte Corporation (marca "Del Monte"), além de algumas empresas japonesas como a Mitsubishi.

O maior produtor mundial é a Tailândia, que em 1993 produziu um total de 2,67 milhões de toneladas (23\% do total), seguido pelas Filipinas com 1,2 milhões de toneladas (10\% do total), Tabela 5 .

A produção dos Estados Unidos vem caindo desde 1970, o que parece ser conseqüência do encarecimento da mão-de-obra e da concorrência da atividade turística no Havai, principal local de produção daquele país.

O Brasil é o principal produtor de abacaxi na América do Sul e terceiro produtor mundial com uma produção variando de 839 mil em 1989 a 820 mil toneladas em 1993.

\subsubsection{Comercialização}

Conforme dados da FAO (6) o volume comercializado em 1992 chegou a 618.969 toneladas de abacaxi exportados. Os principais exportadores têm sido Filipinas, Costa do Marfim e Costa Rica (Tabela 6). 
TABELA 5 - $\begin{gathered}\text { PRINCIPAIS PÁ́SES PRODUTORES DE ABACAXI (EM } 1000 \\ \text { TONELADAS) }\end{gathered}$

\begin{tabular}{|c|c|c|c|c|c|}
\hline PAÍSES & 1989 & 1990 & 1991 & 1992 & 1993 \\
\hline Congo & $115 \mathrm{~F}$ & $12 \mathrm{~F}$ & $12 \mathrm{~F}$ & $12 \mathrm{~F}$ & $12 \mathrm{~F}$ \\
\hline Costa do Marfim & 209 & 196 & 174 & 201 & $240 \mathrm{~F}$ \\
\hline Kênia & 212 & 225 & 245 & 270 & $270 \mathrm{~F}$ \\
\hline África do Sul & 252 & 197 & 210 & 176 & 165 \\
\hline Zaire & 142 & $143 \mathrm{~F}$ & $145 \mathrm{~F}$ & $145 \mathrm{~F}$ & $145 \mathrm{~F}$ \\
\hline Costa Rica & $150 \mathrm{~F}$ & $150 \mathrm{~F}$ & $152 \mathrm{~F}$ & $180 \mathrm{~F}$ & $190 \mathrm{~F}$ \\
\hline Honduras & 129 & $140 \mathrm{~F}$ & $130 \mathrm{~F}$ & $130 \mathrm{~F}$ & $130 \mathrm{~F}$ \\
\hline México & 337 & 455 & 299 & $299 F$ & $300 F$ \\
\hline EUA & 526 & 522 & 504 & 493 & 336 \\
\hline Brasil & 839 & 736 & 779 & 826 & 820 \\
\hline Colômbia & $230 \mathrm{~F}$ & 342 & 345 & 347 & $347 \mathrm{~F}$ \\
\hline Bangladesh & 157 & 162 & 150 & 148 & $150 \mathrm{~F}$ \\
\hline China & 742 & 697 & 923 & 668 & $709 \mathrm{~F}$ \\
\hline Indonésia & 275 & 390 & 375 & $380 \mathrm{~F}$ & $383 F$ \\
\hline Malasia & 216 & 210 & 225 & 244 & $260 \mathrm{~F}$ \\
\hline Filipinas & 1.179 & 1.156 & 1.171 & 1.135 & $1.200 \mathrm{~F}$ \\
\hline Tailândia & 2.005 & 1.865 & 1.931 & 2.438 & 2.674 \\
\hline Vietnan & 485 & 468 & 475 & $500 \mathrm{~F}$ & $519 F$ \\
\hline Austrália & 142 & 126 & 142 & 142 & $145 \mathrm{~F}$ \\
\hline
\end{tabular}

\section{\begin{tabular}{llllll}
\hline MUNDO & 10.194 & 10.034 & 10.256 & 11.455 & 11.740
\end{tabular}}

Fonte: FAO Production Yearbook

$\mathrm{F}=$ Estimativas da FAO 
TABELA 6 - PRINCIPAIS EXPORTADORES DE ABACAXI IN NATURA EM TONELADAS

\begin{tabular}{lrrrr}
\hline PAÍSES & $\mathbf{1 9 8 9}$ & $\mathbf{1 9 9 0}$ & $\mathbf{1 9 9 1}$ & $\mathbf{1 9 9 2}$ \\
\hline & & & & \\
Costa do Marfim & 121.006 & 135.313 & 121.440 & 126.748 \\
Ghana & 7.947 & 9.440 & $10.500 * \mathrm{~F}$ & 10.400 \\
Costa Rica & 100.225 & 95.880 & 100.286 & 110.000 \\
Rep. Dominicana & 31.133 & 47.833 & 55.101 & 65.000 \\
Honduras & 26.838 & 37.700 & 48.744 & 49.073 \\
México & 8.683 & 8.683 & 9.817 & 9.768 \\
Brasil & 12.418 & 7.606 & 15.212 & 16.021 \\
China & 7.107 & 5.183 & 4.273 & 3.456 \\
Malasia & 18.658 & 23.341 & 18.871 & 19.039 \\
Filipinas & 152.055 & 146.323 & 167.520 & 151.754 \\
Bel-Luxemburgo & 17.848 & 7.939 & 5.690 & 7.186 \\
Países Baixos & 14.058 & 13.685 & 18.549 & 15.483 \\
\hline MUNDO & 539.757 & 573.982 & 609.485 & 618.969 \\
\hline
\end{tabular}

Fonte: FAO Trade Yearbook.

$\mathrm{F}=$ Estimativa da FAO.

As exportações para o mercado europeu concentram-se no período de outubro a maio e alcançam seu máximo em dezembro. Durante os meses de verão, em que existe oferta abundante de fruta nacional barata, a demanda de abacaxi se reduz drasticamente.

Os principais fornecedores colocam o abacaxi nos principais Países da Europa durante o ano variando os preços que em épocas de menor demanda tornam-se mais reduzidos.

A Tabela 7 apresenta a época das safras dos Países fornecedores de abacaxi. Praticamente todos os fornecedores estão presentes o ano inteiro, porém em quantidades variáveis. 
TABELA 7 - ÉPOCAS DAS SAFRAS NOS PAÍSES FORNECEDORES DE ABACAXI

\begin{tabular}{|c|c|c|c|c|c|c|c|c|c|c|c|c|}
\hline PAÍS/MESES & JAN & FEV & MAR & $\mathrm{ABR}$ & MAI & JUN & JUL & AGO & SET & OUT & NOV & DEZ \\
\hline Costa do Marfim & $\ddot{Q}$ & 2 & & & & & & & & & & \\
\hline Ghana & & & & & & & & & & & & \\
\hline Guinea & & & & & $\ell$ & 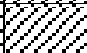 & $\mathscr{Z}$ & & & & & \\
\hline Camarões & & & & & & & & & & & & \\
\hline Costa Rica & & & & & & & & & & & & \\
\hline Honduras & & & & & & & & & & & & \\
\hline República & & & & & & 2 & 2 & $\ell$ & थ & & & 2 \\
\hline Dominicana & 2 & 2 & $2 Q$ & & & & 2 & & $\mathrm{Zl}$ & & & \\
\hline México & 2 & & 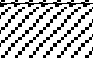 & & & & 2 & & & & & 2 \\
\hline Hawai & & & & & & & & & & & & 2 \\
\hline África do Sul & 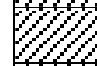 & & & & & & & & & & & \\
\hline Brasil & $\ell$ & ${ }_{Z Z}$ & & & & & & & & & & \\
\hline
\end{tabular}

Fonte: IBRAF/DATAFRUTA/MARÇO 1993.

22

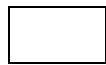

||||||||

Os principais países importadores de abacaxi, em 1993, foram - Japão com 127.466 toneladas, seguido pelos EUA com 123.680 toneladas. A França maior importador europeu é responsável por $12 \%$ das importações mundiais com 75.967 toneladas (Tabela 8 ).

- Tabela 9 apresenta as variações dos preços médios de importações em 1992 pelos principais países importadores. Os maiores preços são pagos pelo Reino Unido e França. Os EUA pagam preço 61\% menor que o Reino Unido e 49\% menor que a França.

Como mercado potencial pode-se citar os Estados Unidos que apesar de grandes produtores são também importantes clientes, - Canadá que não conta com produção própria (atualmente importa dos Estados Unidos) e Europa que vem apresentando importância crescente nos últimos anos.

As importações mundiais de abacaxi “in natura” fresco que vinham se mantendo ao redor das $537 \mathrm{mil}$ toneladas no período de 1987/89 chegaram em 1992 a $629 \mathrm{mil}$ toneladas e US\$374 milhões de dólares (Tabelas 8 e 9). o preço médio das importações é de US\$603/toneladas que são realizadas a preços diferentes conforme a origem o que eleva o preço médio de cada país; os produtos geralmente são reexportados dentro do mercado Europeu após sua entrada principalmente através dos Países Baixos. 
O abacaxi "in natura" fresco é bem conhecido no mercado francês. Os consumidores ao contrário de outros países não consideram o abacaxi como artigo de luxo, tendo adquirido a condição de fruta comum geralmente consumida como sobremesa (16).

TABELA 8 - PRINCIPAIS IMPORTADORES DE ABACAXI “IN NATURA" EM TONELADAS

\begin{tabular}{lrrrrr}
\hline PAÍSES & $\mathbf{1 9 8 9}$ & $\mathbf{1 9 9 0}$ & $\mathbf{1 9 9 1}$ & $\mathbf{1 9 9 2}$ \\
\hline Canadá & 15.786 & 17.192 & 17.216 & 17.794 \\
EUA & 98.448 & 113.885 & 115.155 & 123.680 \\
Argentina & 8.950 & 11.986 & 15.872 & 16.819 \\
Hong Kong & 7.997 & 8.291 & 5.019 & 4.138 \\
Japão & 135.383 & 128.250 & 137.786 & 127.466 \\
Singapura & 13.026 & 13.399 & 15.372 & 15.707 \\
Bel-Luxemburgo & 33.323 & 50.203 & 45.699 & 53.068 \\
França & 68.936 & 80.166 & 86.055 & 75.967 \\
Alemanha & 34.175 & 40.533 & 42.210 & 45.153 \\
Itália & 36.088 & 40.499 & 41.799 & 50.647 \\
Países Baixos & 14.058 & 13.685 & 18.549 & 15.483 \\
Espanha & 19.614 & 20.281 & 23.872 & 25.129 \\
Reino Unido & 20.008 & 20.749 & 21.042 & 20.705 \\
& & & & 628.960 \\
\hline MUNDO & 537.335 & 595.607 & 624.225 &
\end{tabular}

Fonte: FAO Trade Yearbook.

TABELA 9 - PREÇOS MÉDIOS DE IMPORTAÇÃO DE ABACAXI, NOS PRINCIPAIS PAÍSES IMPORTADORES, EM 1992

\begin{tabular}{lr}
\hline PAÍSES & PREÇO US\$/TON. \\
\hline Canadá & 565,00 \\
Estados Unidos & 423,00 \\
Argentina & 317,00 \\
Hong Kong & 452,00 \\
Japão & 447,00 \\
Singapura & 124,00 \\
Bel-Luxemburgo & 573,00 \\
França & 832,00 \\
Alemanha Federal & 623,00 \\
Itália & 812,00 \\
Países Baixos & 621,00 \\
Espanha & 991,00 \\
Reino Unido & $1.094,00$ \\
\hline MUNDO & 603,00 \\
\hline
\end{tabular}

Fonte: FAO Trade Yearbook 1992. 
o mercado mais sofisticado é abastecido por fruta transportada via aérea principalmente da Costa do Marfim, que devido a redução da área plantada e falta de tecnologia, vem abrindo mercado para outros exportadores.

A preferência (90\%) é pela fruta do tamanho 1,1 a 1,5 kg e 0,9 a $1,1 \mathrm{~kg}$ e são as que obtém preços mais altos no mercado (10) .

Os preços no mercado externo variam segundo a origem, tipo de transporte, tamanho da fruta e época.

\subsection{Exportações brasileiras}

O Brasil não possui tradição exportadora no que se refere ao abacaxi “in natura”, apesar de ocupar a posição de terceiro maior produtor mundial. Isso é decorrente da produção brasileira destinar-se basicamente para o consumo doméstico.

A Tabela 10 apresenta as exportações brasileiras no período de $1987 / 94$ por principais importadores em quantidade (kg) e valores em (US\$).

Em 1991 o Brasil retoma às $15 \mathrm{mil}$ toneladas exportadas em 1987 e registra crescimento de 87\% em relação aos dados do Banco do Brasil para o ano de 1990. Os dados de 1994 somam aproximadamente $23 \mathrm{mil}$ toneladas e US\$ 7 milhões de dólares.

Os preços médios de venda no período analisado, estão ao redor de US\$300/t, destacando-se o ano de 1990 com US\$ 390/t.

Destacaram-se como principais importadores, nos últimos anos, a Argentina, a Bélgíca e o Uruguai (Tabela 11).

No ano de 1993, elevação no total exportado, reforça a recuperação das exportações com $36 \mathrm{mil}$ toneladas (Tabela 11).

Os países do Mercosul que eram responsáveis pela importação de 91\% do abacaxi brasileiro, passaram em 1993 a representar 70\% do volume exportado. Em 1994 chegaram a participação de apenas 35\% devido a drástica redução de importação argentina que passou de $24 \mathrm{mil}$ toneladas em 1993 para 7 mil toneladas nesse último ano (4).

As empresas brasileiras exportadoras de abacaxi fresco nos anos de 1993/94 com os respectivos valores são apresentadas no Tabela 11 . 
TABELA 10 - EXPORTAÇÃO BRASILEIRA DE ABACAXI “IN NATURA” POR PAÍSES IMPORTADORES

NO PERÍODO DE 1987 A 1992

\begin{tabular}{|c|c|c|c|c|c|c|c|c|c|c|c|c|c|c|c|c|}
\hline \multirow{2}{*}{$\begin{array}{c}\text { PAÍSES } \\
\text { IMPORTADORES }\end{array}$} & \multicolumn{2}{|c|}{1987} & \multicolumn{2}{|c|}{1988} & \multicolumn{2}{|c|}{1989} & \multicolumn{2}{|c|}{1990} & \multicolumn{2}{|c|}{1991} & \multicolumn{2}{|c|}{1992} & \multicolumn{2}{|c|}{1993} & \multicolumn{2}{|c|}{1994} \\
\hline & $\mathrm{t}$ & US\$ & $\mathrm{t}$ & US\$ & $\mathrm{t}$ & US\$ & $\mathrm{t}$ & US\$ & $\mathrm{t}$ & US\$ & $\mathrm{t}$ & US\$ & $\mathrm{t}$ & US\$ & $\mathrm{t}$ & US\$ \\
\hline Alemanha Ocidental & 20 & 5,070 & 46 & 12.919 & - & - & - & - & - & - & 4 & 9.550 & 3 & 3.367 & 301 & 75.670 \\
\hline Angola & - & - & 0,2 & 246 & - & - & - & - & - & - & - & - & 1 & 1.548 & - & - \\
\hline Argentina & 13.598 & 3.968.146 & 8,932 & 2.717.244 & 10.807 & 3.264 .581 & 7.143 & 2.873.131 & 14.792 & 4.945 .884 & 14.868 & 4.876 .996 & 23.973 & 6.984 .518 & 7.232 & 2.382.741 \\
\hline Áustria & 0,5 & 240 & 0,005 & 1 & 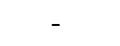 & - & & - & - & - & . & 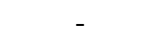 & & & & \\
\hline Bélgica & 10 & 2.696 & 243 & 60.681 & 842 & 210.401 & 216 & 53.932 & - & - & 287 & 71.681 & 9.383 & 2.493 .920 & 14.115 & 4.066 .598 \\
\hline Espanha & 1.105 & 301.706 & 390 & 100.395 & 237 & 56.221 & 8 & 3.960 & 177 & 38.886 & - & - & 1.189 & 323.302 & 72 & 25.905 \\
\hline Grécia & - & - & 150 & 30.291 & - & - & - & - & - & - & - & - & - & - & - & - \\
\hline Japão & - & - & 0,5 & 138 & 0,4 & 149 & - & - & - & - & - & - & - & - & - & - \\
\hline Países Baixos & 35 & 8.851 & 249 & 43.324 & 111 & 27.738 & 0,5 & 129 & 0,6 & 1.934 & 25 & 6.653 & 25 & 6.762 & 175 & 49.508 \\
\hline Portugal & - & - & 28 & 12.566 & 1 & 663 & 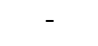 & - & - & & 14 & 13.700 & 5 & 3.240 & 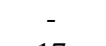 & 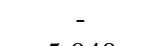 \\
\hline Reino Unido & 37 & 10.734 & 291 & 72.793 & 129 & 32.205 & - & - & 27 & 5.863 & 122 & 33.969 & 41 & 20.040 & 17 & 5.040 \\
\hline Uruguai & 297 & 95.073 & 476 & 151.156 & 242 & 74.810 & 521 & 174.525 & 196 & 62.470 & 831 & 261.038 & 1.327 & 396.151 & 690 & 254.166 \\
\hline Dinamarca & 13 & 3.186 & - & - & - & - & 9 & 4.500 & - & - & - & - & - & - & - & - \\
\hline França & 22 & 5.645 & - & - & - & - & & - & - & - & - & - & - & - & - & - \\
\hline Itália & 63 & 23.218 & - & - & 50 & 12.410 & 13 & 3.220 & 2 & 2.333 & 4 & 2.780 & 0,052 & 11 & & \\
\hline Suíça & - & - & - & - & 0,10 & 48 & - & - & - & - & - & - & - & - & - & - \\
\hline Chile & & & & & & & & & & & & - & 0,020 & 146 & 0,020 & 146 \\
\hline Canadá & & & & & & & & & & & & - & & & 0,020 & 20 \\
\hline Estados Unidos & & & & & & & & & & & & - & - & & 1 & 15.677 \\
\hline Paraguai & & & & & & & & & & & & & - & & 19 & 7.622 \\
\hline Anguila & & & & & & & & & & & 9 & 2.500 & - & & & \\
\hline TOTAL & 15.200 & 4.424 .565 & 10.806 & 3.201 .754 & 12.419 & 3.679 .226 & 7.910 & 3.113.397 & 15.189 & 5.057 .370 & 16.165 & 5.278 .467 & 35.948 & $\begin{array}{c}10.233 .00 \\
5 \\
\end{array}$ & 22.622 & 6.883 .093 \\
\hline US\$/t & & 290 & & 290 & & 290 & & 390 & & 330 & & 326 & & 285 & & 300 \\
\hline
\end{tabular}

Fonte: Branco do Brasil - DECEX. 
TABELA 11 - PRINCIPAIS EMPRESAS BRASILEIRAS EXPORTADORAS DE ABACAXI FRESCO OU SECO NO ANO DE 1993 E 1994

\begin{tabular}{|c|c|c|}
\hline EMPRESAS EXPORTADORAS & 1993 US\$ FOB & 1994 US\$ FOB \\
\hline Imp. e Exp. Irmãos Zeffa & 202.500 & 16.500 \\
\hline Agroexport Imp. e Export. de frutas & 40.500 & 6.500 \\
\hline Geminis Imp. e Exp. Ltda. & 100.000 & 34.774 \\
\hline Alfros Ind. Com. Imp. e Exp. de Prod. Alimentícios & 6.200 & 2.750 \\
\hline Frutal Imp. Exp. Com. de Hortigrangeiros e Cereais Ltda. & 39.796 & 27.485 \\
\hline Rudi Bonow e Cia. & 64.760 & 39.230 \\
\hline Seneal Com. de Exp. Imp. e transporte Ltda. & 100.436 & 9.000 \\
\hline J.A. Winckler & 297.700 & 138.650 \\
\hline R. Malatesta \& Cia. Ltda & 141.980 & 3.900 \\
\hline RJU Comércio Beneficiamento de Frutas e Verduras Ltda & 72.758 & 64.980 \\
\hline Agroindustrial Ltda. & - & 95.075 \\
\hline Salvia \& Mamede Ltda. & 318.640 & 96.075 \\
\hline Frutícola Haydar Ltda. & 83.058 & 50.325 \\
\hline Frutaboa Ltda & 133.902 & 14.875 \\
\hline Cooperativa Agrícola de Cotia & 305.599 & \\
\hline Claísa Comercial Imp. Exp. & 22.680 & \\
\hline Marinei Comércio Imp. e Exp. Ltda & 2.817 .060 & 1.245 .630 \\
\hline Eldorado Comercial Agrícola & 55.000 & \\
\hline El Gringo Comércio Imp. e Exp. De Frutas & 112.961 & 50.000 \\
\hline Fazenda Dia Fruits Ltda. & 320.000 & - \\
\hline Benassi Campinas Exp. Imp. Ltda. & 50.370 & 21.000 \\
\hline Expofrut Com. Imp. e Exp. Ltda & 270.017 & 62.622 \\
\hline Exifruta Comércio Imp. e Exp.de frutas Ltda. & 143.000 & 52.200 \\
\hline Mamut Com. Exp. e Imp. & 138.358 & 32.075 \\
\hline Exportadora e Imp. Recibal Ltda. & 3.870 & - \\
\hline Yamazato Comércio e Empreendimentos Imobiliários & 159.594 & 11.400 \\
\hline Frutícola Cacique & 223.865 & 143.050 \\
\hline Guaraú Comércio Ext. & 183.705 & 22.095 \\
\hline Exportadora Joraik Ltda. & 204.350 & 88.631 \\
\hline Exportadora Irmãos Cury Ltda. & 139.725 & 37.950 \\
\hline Sandim \& Moura Ltda. & 139.725 & 139.725 \\
\hline Frunorte Frutas do Nordeste & - & 5.040 \\
\hline Imcompasa Ind. De Compotas Paraíba & 20.040 & 131.898 \\
\hline Brasfrutas S.A. & 2.416 .310 & 3.934 .700 \\
\hline Tropik-Bras.Com.Imp. e Exp. & - & 12.420 \\
\hline Climport - Com. e Imp. de Alimentos & - & 12.750 \\
\hline
\end{tabular}

Fonte: DECEX. 
A maioria das exportações (80\%) são despachadas por via terrestre (porto de Uruguaiana) em caminhões frigoríficos para a Argentina e Uruguai. As destinadas para Europa utilizam os aeroportos de João Pessoa, Recife, Rio de Janeiro, Guarulhos e Campinas, sendo enviados principalmente para os Países Baixos, o Reino Unido e a Espanha. Os exportadores brasileiros que apresentam maior volume de transação tem sido as empresas Brasfrutas S.A e Marinei Com. Imp. e Exp. Ltda. (Tabela 11). Os principais concorrentes são a Costa do Marfim, Costa Rica, Filipinas e Honduras (Tabela 7) .

Os custos de comercialização incorridos na exportação variam em função da origem e destino da fruta.

Segundo o Instituto Brasileiro de Frutas (10), a exportação de abacaxi pelo Porto do Rio de Janeiro, por exemplo, para a Holanda via Rotterdam, envolve nas diferentes fases da comercialização, as despesas relacionadas no Esquema 1.

\section{ESQUEMA 1 - ESTRUTURA DA COMERCIALIZAÇÃO DO ABACAXI "IN NATURA"}

\section{\begin{tabular}{ll}
\hline Preços de venda no atacado em Rotterdam & US\$ X.XX/cX
\end{tabular}}

( - ) Comissão Importador

(-) Custos desembaraço no porto

(-) Imposto de importação

(-) Transporte

(-) Distribuição ("handling”)

(-) Frete marítimo Rio/Rotterdam

(-) Custo embarque

(-) Custos armazenagem frigorificada

(-) Custos transporte até o porto

(-) Custos pré-resfriamento

(-) Custos caixa papelão, acessórios

(-) Custos administrativos

Saldo Líquido............... US\$ Z.ZZ/cx

(*) As quantidades importadas são limitadas, existindo quotas distribuídas a cada importador habitual. 


\subsection{PACKING HOUSE PARA O ABACAXI}

\subsubsection{Manuseio pós colheita}

Os frutos transportados a granel do campo para o Packing House são descarregados próximos à mesa de seleção. Após este processo, corta-se o pedúnculo na medida exata de 2 a $3 \mathrm{~cm}$ de acordo com exigência para sua exportação.

Os frutos são conduzidos para um tanque contendo solução de fungicida (Benomil 0,1\% mais espalhante adesivo 0,05\%) para a desinfecção do pedúnculo. Após permanência por 2 minutos nesta solução, os frutos são retirados e colocados em esteira de roletes para escorrimento da solução e em seguida passam pelo túnel de secagem. Através de uma esteira alimentadora são conduzidos para as classificadoras por peso. Nesta fase são separados e acondicionados em caixas de papelão, as quais são pesadas, imediatamente fechadas, rotuladas e paletizadas. Completado o palete este é conduzido para câmara de aquecimento, que uma vez completada com 16 paletes será acionada para $37^{\circ} \mathrm{C}$, devendo as frutas permanecerem nesta temperatura durante 24 horas. Quando retirados desta câmara de tratamento térmico são colocados em câmara de resfriamento a $10^{\circ} \mathrm{C}$, enquanto aguardam 0 embarque.

\subsubsection{Capacidade diária e anual de produção e exportação}

O abacaxi da variedade Smooth Cayenne, com a safra estipulada no período de outubro a fevereiro, deverá dispor de uma unidade de Paking House com período de trabalho de 5 meses ao ano.

A unidade diária e anual de produção de matéria-prima é estimada em $30.720 \mathrm{~kg} / \mathrm{dia}$ ou $3.840 .000 \mathrm{~kg} / \mathrm{ano}$.

A seleção para a exportação é estabelecida em $9.216 \mathrm{~kg}$ ou 16 paletes ( 2 containers) ou ainda $1.152 .000 \mathrm{~kg}$, sendo 2000 paletes (250 containers) ao ano.

A embalagem deverá ser uma caixa de papelão com capacidade para $8 \mathrm{~kg}$, medindo $390 \times 250 \times 275 \mathrm{~mm}$.

\subsubsection{Equipamentos e mão-de-obra}

Os equipamentos necessários para o funcionamento do Packing House referem-se aos de manuseio pós-colheita e auxiliares, os quais estão relacionados na Tabela 12, totalizando US\$ $99.100,00$. 
Quatro funcionários caracterizarão a mão-de-obra indireta ou não produtiva e 37 funcionários a mão-de-obra direta ou produtiva.

TABELA 12 - EQUIPAMENTOS NECESSÁRIOS AO PACKING HOUSE

\begin{tabular}{|c|c|}
\hline $\begin{array}{l}\text { EQUIPAMENTO PARA O MANUSEIO PÓS- } \\
\text { COLHEITA }\end{array}$ & EQUIPAMENTOS AUXILIARES \\
\hline $\begin{array}{l}\text { - uma esteira de seleção } \\
\text { - um tanque para aplicação de solução de fungicida } \\
\text { - uma esteira de roletes } \\
\text { - um sistema de ventilação forçada para secagem } \\
\text { - uma esteira alimentadora } \\
\text { - três classificadoras por peso } \\
\text { - duas balanças } \\
\text { - duas mesas para acondicionamento, pesagem, } \\
\text { fechamento e rotulagem das caixas } \\
\text { - uma câmara de aquecimento a } 37^{\circ} \mathrm{C} \text { (tratamento } \\
\text { térmico) } \\
\text { - uma câmara frigorífica a } 10-12^{\circ} \mathrm{C} \text { para resfriamento } \\
\text { - um painel elétrico para comando e proteção }\end{array}$ & $\begin{array}{l}\text { - um sistema de frio completo para } \\
\text { câmara } \\
\text { - uma caixa d'água elevada de } 30 \mathrm{~m}^{3} \\
\text { - uma cabina medidora } \\
\text { - uma cabina transformadora de } 150 \mathrm{KVA}\end{array}$ \\
\hline SUB-TOTAL US\$ 82.800,00 & US\$ 16.300,00 \\
\hline
\end{tabular}

\subsubsection{Investimento} A estimativa dos investimentos é apresentada no Tabela 13 e
totaliza US\$ $274.936,00$.

O item veículos refere-se a um Caminhão Mercedez, mod. 70937, uma pick-up e duas paleteiras, mod. BXLG-1000, totalizando US\$ 51.600,00 dólares. 
TABELA 13 - ESTIMATIVA DOS INVESTIMENTOS NECESSÁRIOS INSTALAÇÃO DE PACKING HOUSE

\section{ITENS}

VALORES EM

US\$

\begin{tabular}{lr}
\hline - Estudos e projeto & $6.600,00$ \\
- Terreno de 2,600m² e obras de terraplenagem & $26.000,00$ \\
- Obras civis & $64.120,00$ \\
- Equipamentos de manuseio da mão-de-obra & $82.800,00$ \\
- Equipamentos auxiliares & $16.300,00$ \\
- Veículos & $51.600,00$ \\
- Móveis e instalações de escritório & $7.200,00$ \\
- Montagem e instalações & $9.910,00$ \\
- Imprevistos & $10.406,00$ \\
\hline
\end{tabular}

\section{TOTAL}

US\$ $274.936,00$

Fonte: ITAL (13).

o fluxograma quantitativo básico estabelecido para uma unidade de packing house está apresentado na Figura 2.

A utilização de packing house adequados propiciará a obtenção e manutenção dos padrões de qualidade que vêm sendo um dos principais entraves relacionados com a comercialização da fruta "in natura”.

\section{CONCLUSÃO}

A maioria do consumo de abacaxi no mercado interno envolve a forma “in natura” e a variedade Pérola. Quando se pretende estabelecer comercialização no mercado externo a variedade preferida deverá ser "Smooth Cayenne". 
FIGURA 2 - FLUXOGRAMA QUANTITATIVO BÁSICO PARA UMA UNIDADE DE PACKING HOUSE

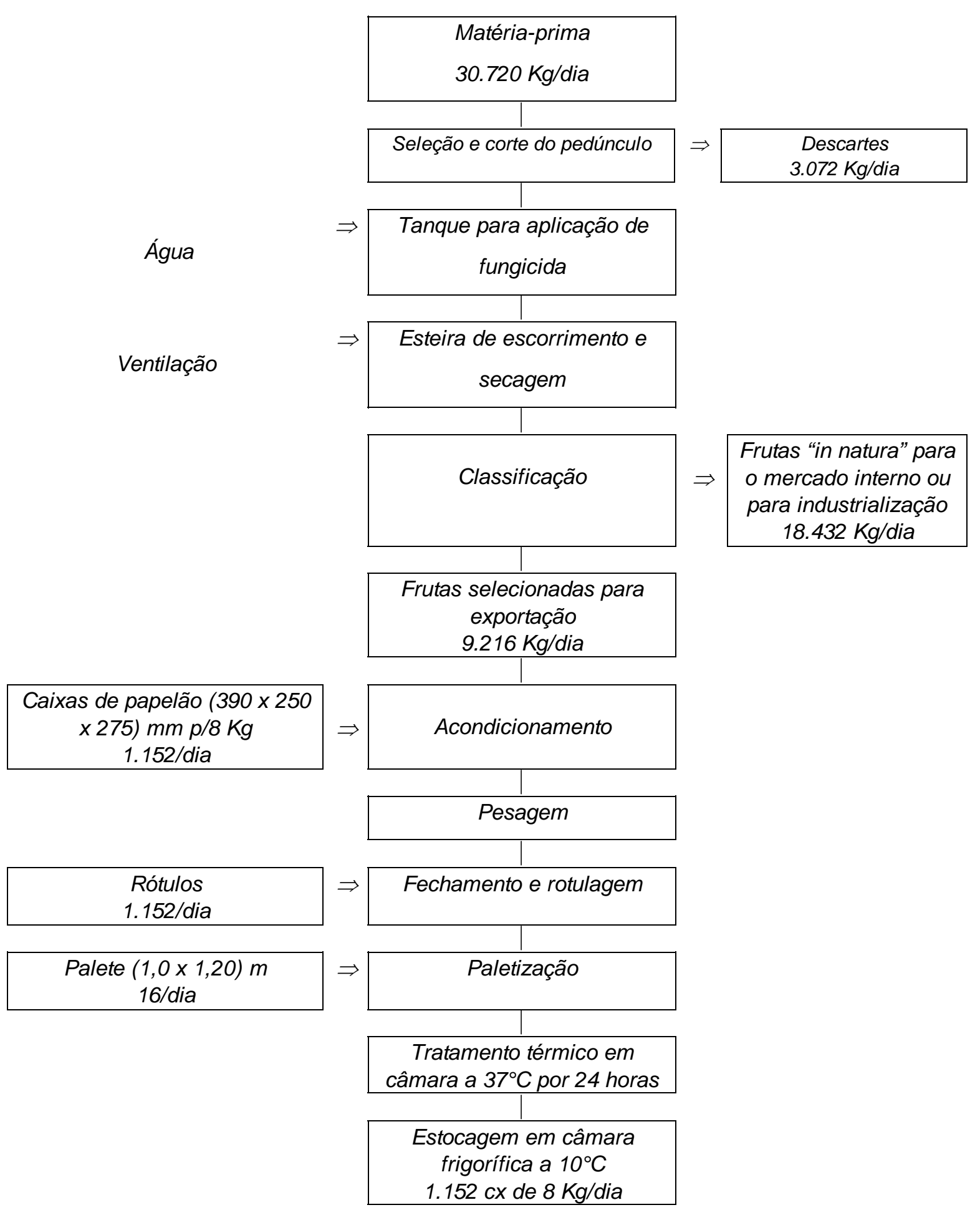


O estabelecimento de packing house atuará fundamentalmente na seleção e padronização do abacaxi para o mercado interno e externo. Com investimento da ordem de US\$275.000,00 o setor estará colaborando na solução dos principais entraves à comercialização da fruta “in natura”, ou seja, manutenção dos padrões de qualidade (o aspecto verde mesmo após maturação são menos aceitos); tecnologia pós-colheita inadequada; falta de armazenamento frigorificado; preço elevado; dificuldade e custo de transporte; preferências por diferentes variedades; exigências fitossanitárias; concorrência com maiores exportadores com vantagens geográficas e tarifárias (Costa do Marfim e Gana).

Como perspectivas pode-se citar:

- um levantamento edafoclimático indicará as regiões mais propícias ao cultivo, e a possibilidade de se estabelecer tratamentos fitossanitários adequados propicia o incremento da produção;

- o declínio da produção e qualidade do abacaxi exportado pela Costa do Marfim, devido a redução da área plantada e falta de tecnologia, vem abrindo mercado para outros exportadores;

- a cultura orientada para a variedade adequada, o controle de pragas e o atendimento das características de cor, aspecto e peso contará com boas perspectivas no mercado externo.

O aproveitamento industrial do abacaxi não é limitado pelas variedades, ou seja, poderão ser industrializadas frutas das duas variedades, tanto as sobras dos packing-houses, quanto as frutas destinadas integralmente a industrialização, na forma principalmente de sucos simples para a mercado interno e sucos concentrados para o mercado externo.

\section{Abstract}

Agroindustry development in the fruit sector is directly related to the growth and the modernization of the market. Brazil is one of the main pineapple producing countries being among the top ten exporters. The supply and demand situation in general, as well as the potencial and requirements of foreing markets and the use of appropriate packing houses, are factors influencing the success of the pineapple agroindustry. With an investiment of approximately US\$275.000,00 for the installation of one packing house, the sector will be helping to obtain the quality standards which are one of the main barriers to the commercialization of "in natura” fruit. 


\section{REFERÊNCIAS BIBLIOGRÁFICAS}

1 ALMEIDA, L.A.S.B., BLEINROTH, E.W., MORETTI, V.A., BICUDO NETO, L.C., RIVELLI, P.B. Comercialização de frutas tropicais: estudos econômicos. Alimentos Processados, Campinas, n. 25, p. 106, 1987.

2 O MERCOSUL e o papel dos agentes e representantes comerciais. B. da Revista Comércio Exterior, n.351 Brasilia, dez. 1991.

3 COOPERATIVA AGRÍCOLA COTIA. Banco de Dados. [S.1. : s.n.], 1993 .

4 DECEX. Departamento de Comércio Exterior. Secretaria de Comércio Exterior. Banco de Dados. Rio de Janeiro, 1994 .

5 FAO Production Yearbook. Relações Roma, V. 42/48, n. $88 / 125,1988 / 1994$.

6 FAO Trade Yearbook. Roma, v. 43/47, 96/121, 1988/1994.

7 FUNDAÇÃO INSTITUTO BRASILEIRO DE GEOGRAFIA E ESTATÍSTICA. Anuário Estatístico do Brasil. Rio de Janeiro, 1993. p. 2

8 FUNCEX. Dados estatísticos: expotações. R. Brasileira de Comércio Exterior (RBCE). Rio de Janeiro, dez. 1993.

9 HORTINEXA. Associação Nacional dos Exportadores de Hortigrangeiros: banco de dados. São Paulo, 1993.

10 IBRAF. Instituto Brasileiro de Frutas. Banco de dados/datafruta. São Paulo, 1994.

11 INSTITUTO de Economia Agrícola: informações econômicas. São Paulo, 1994 .

12 INSTITUTO DE TECNOLOGIA DE ALIMENTOS. Série Frutas Tropicais, Campinas, n. 2, 1987.

13 INSTITUTO DE TECNOLOGIA DE ALIMENTOS. Banco de dados: Seção de Economia. São Paulo, Campinas, 1994.

14 INTERNATIONAL Fruits World. Fruit Flash, Suiça, V.49, n. $1,1991$.

15 ITC. International Trade Center. Tropical fruit juice and pulp. Genebra, 1990. 304 p.

16 IRFA. Institute de Reserches sur les Fruits et a agrumes: fruits les importations de fruits tropicaux et d'agrumes. Fruits, França, v. 47, n. 2, p. 349-373, 1992 . 
17 UNIVERSIDADE DE SÃO PAULO. Secretaria de Estado da Ciência, Tecnologia e Desenvolvimento Econômico. Identificação do potencial de oferta exportável de produtos hortigrangeiros selecionados: relatório de pesquisa. Piracicaba, 1990. $143 \mathrm{p}$. 